\title{
Carotid Artery Encasement by Thyroid Carcinoma
}

\author{
Sabaretnam Mayilvaganan, Pooja Ramakant, Deepak T Abraham, MJ Paul
}

How to cite this article: Mayilvaganan S, Ramakant P, Abraham DT, Paul MJ. Carotid Artery Encasement by Thyroid Carcinoma. World J Endoc Surg 2013;5(1):31-32.

\section{Source of support: Nil}

\section{Conflict of interest: None}

A 22 years old gentleman presented in our outpatient clinic with history of having undergone neck exploration at another center in August 2012 for medullary thyroid cancer. Total thyroidectomy was deemed inoperable as the mass was fixed to the carotid and trachea; a debulking procedure with bilateral modified radical neck dissection was performed. He presented with a residual painful swelling in the left side of the neck for 2 months. Local examination revealed scar of the previous operation with tender, hard, fixed left paratracheal mass and matted lymph nodes in level 4 and level 5 of the left side of neck. There was ptosis and miosis of the left eye. The left carotid and superficial temporal pulses were palpable but diminished. The contrast enhanced computerized tomogram showed complete encasement of left carotid artery (Fig. 1). There were no features of luminal irregularity to suggest transmural involvement.

The patient underwent surgery and intraoperatively we found a hard, infiltrating mass of confluent thyroid and nodes in the left paratracheal region encasing the left common carotid for a length of $7 \mathrm{~cm}$ (Fig. 2). The carotid sheath was entered and the carotid artery dissected in the subadventitial plane (peeling) along the whole length of involvement to release the encasing tumor and taped for retraction. We would like to emphasize the fact that contrast enhanced computed tomography (CECT) is not accurate in demonstrating malignant invasion of the carotid artery. ${ }^{1-3}$ The carotid artery is resistant to transmural involvement for a prolonged period of invasion, probably on account of its pulsatile movement. Excision of the encasing tumor from carotid artery by dissecting in the subadventitial plane (peeling) is an effective technique if the tumor involvement is less than $180^{\circ} .{ }^{4}$ However, complete encasement on CECT as in this case need not signify inoperability or necessitate carotid artery resection.

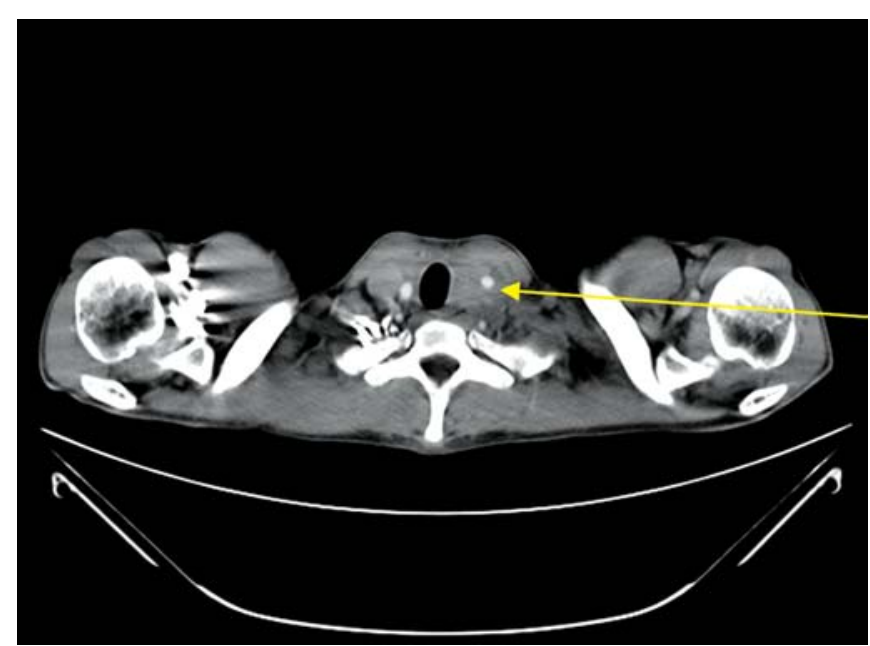

Fig. 1: CECT showing encasement of common carotid artery

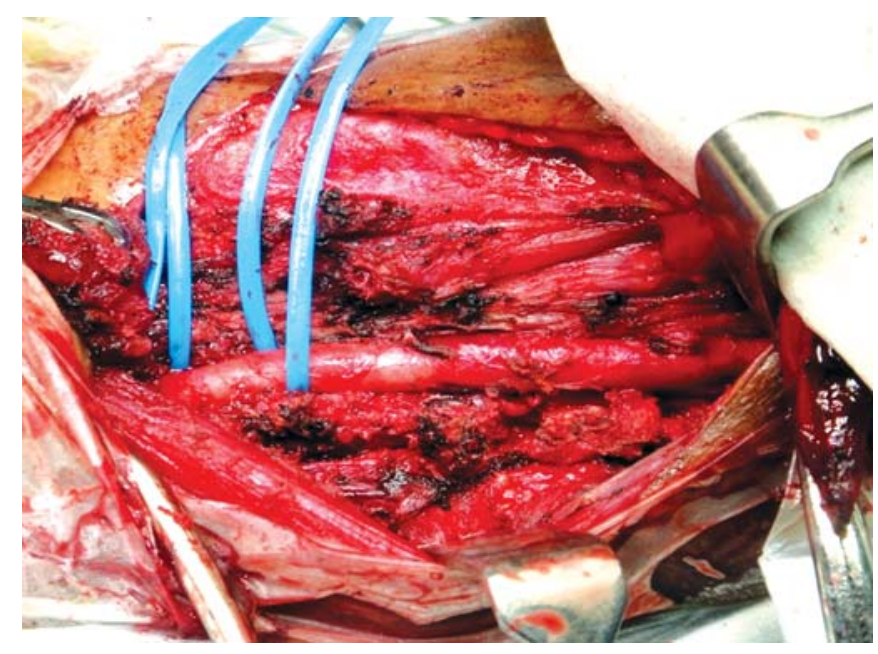

Fig. 2: Intraoperative photograph showing carotid artery encasement

\section{REFERENCES}

1. Rothstein SG, Persky MS, Horii S. Evaluation of malignant invasion of the carotid artery by CT scan and ultrasound. Laryngoscope 1988 Mar;98(3):321-24.

2. Yu Q, Wang P, Shi H, Luo J. Carotid artery and jugular vein invasion of oral-maxillofacial and neck malignant tumors: Diagnostic value of computed tomography. Oral Surg Oral Med Oral Pathol Oral Radiol Endod 2003 Sep;96(3):368-72.

3. Zaragoza L, Sendra F, Solano J, Garrido V, Martínez-Morillo M. Ultrasonography is more effective than computed tomography in excluding invasion of the carotid wall by cervical lymphadenopathies. Eur J Radiol 1993 Nov;17(3):191-94.

4. Yoo GH, Hocwald E, Korkmaz H, Du W, Logani S, et al. Assessment of carotid artery invasion in patients with head and neck cancer. Laryngoscope 2000 Mar;110(3 Pt 1):386-90. 
Sabaretnam Mayilvaganan et al

\section{ABOUT THE AUTHORS}

\section{Sabaretnam Mayilvaganan (Corresponding Author)}

Assistant Professor, Department of Endocrine Surgery, Christian Medical College, Vellore, Tamil Nadu, India, e-mail: drretnam@gmail.com

\section{Pooja Ramakant}

Associate Professor, Department of Endocrine Surgery, Christian Medical College, Vellore, Tamil Nadu, India

Deepak T Abraham

Professor, Department of Endocrine Surgery, Christian Medical College, Vellore, Tamil Nadu, India

\section{MJ Paul}

Professor and Head, Department of Endocrine Surgery, Christian Medical College, Vellore, Tamil Nadu, India 